In these units there is a real problem in maintaining familiarity and skill with flying squad equipment, which is now so rarely used. To abandon the services abruptly, however, would undoubtedly jeopardise maternal safety in home confinements and GP units. Although the percentage of births taking place outside consultant units has fallen considerably in the past few decades, a constant level has now been reached, and, although very low, it still has to be accounted for when planning anaesthetic services. Even in cases where no anaesthetic is given, the anaesthetist's unique skills in resuscitation may still be life saving. Although the normal emergency services will often be able to bring potential flying squad cases rapidly to hospital, it is not impossible to picture circumstances in which this might not be possible.

The recent changes in flying squad practice may well herald the withdrawal of the service in urban areas, but can this reasonably be proposed in rural areas? If the service is to continue in some form then the major problem to be dealt with is that of the inevitable inexperience among junior staff.

Department of Anaesthetics,

C C Callander

Singleton Hospital,

Swansea SA2 8QA

1 Callander CC, Hutton P. The anaesthetist and the obstetric flying squad. Could complacency creep in? Anaesthesia 1986;41 712-5.

SIR,-Dr T D Ryan and Mr G M Kidd question the continuing need for obstetric flying squads.

Leicestershire Health Authority has a population of 860000 people, and about 11000 women are delivered each year; about 1400 are delivered in six peripheral obstetric units. During 1977-86, 205 of the 605 calls to the obstetric flying squad in Leicestershire were to these six small obstetric units, some of which are up to 17 miles from Leicester (table). The number of calls ranged from

Proportion of calls to Leicestershire's flying squad that were to peripheral units $1977-86$

\begin{tabular}{cccc}
\hline & & \multicolumn{2}{c}{ Calls to peripheral hospital: } \\
\cline { 3 - 4 } Year & $\begin{array}{c}\text { Total } \\
\text { fying } \\
\text { squad } \\
\text { calls }\end{array}$ & Total & $\begin{array}{c}\text { Necessitating } \\
\text { transfer to } \\
\text { base hospital }\end{array}$ \\
\hline 1977 & 53 & 16 & 4 \\
1978 & 48 & 18 & 4 \\
1979 & 48 & 22 & 5 \\
1980 & 77 & 26 & 8 \\
1981 & 73 & 23 & 7 \\
1982 & 59 & 26 & 5 \\
1983 & 75 & 17 & 5 \\
1984 & 62 & 17 & 2 \\
1985 & 56 & 25 & 6 \\
1986 & 54 & 15 & 6 \\
\hline Total & 605 & $205(34 \%)$ & $52(8 \cdot 6 \%)$ \\
\hline
\end{tabular}

15 to 26 a year. Most of the calls were for retained placentas, which were removed under genera or epidural anaesthesia at the peripheral unit; 52 patients were transferred to the main hospitals The remainder of the calls were to patients' homes for antepartum or postpartum haemorrhages, hypertension, etc.

Such a service is demanding of medical and nursing time, and the on call registrars were away from base hospitals for up to three hours, thus necessitating alternative cover. As long as peripheral maternity units exist in Leicestershire there will be a need for an obstetric flying squad.

A D G ROBERTS C A J MACAFEE Leicester Royal Infirmary Maternity Hospital, Leicester LE1 5WW
Outbreak of Weil's disease in a food fad commune in India

SIR,-The epidemiological investigations by Dr Pradip K Agrawal and Professor D K Srivastave seem to be far from complete enough to prove that leptospirosis in a Mussahar community developed through eating rat meat and not through other wel known modes of transmission. Being brought up in a village in Bihar, where there is a large Mussahar community, I would like to point ou that Mussahars are not a wandering community; they live outside a particular village through many generations. Several of their activities would make them especially at risk of leptospirosis.

(1) They are agricultural labourers engaged in cutting and handling paddy crops, which may be contaminated with rats' urine. (2) They catch field rats by digging out the rat's hole and pouring water in it. (3) They dig mud with their bare hands in the ponds to catch underwater snakes. (4) They bathe and wash in ponds, which may have many rat holes on the banks. It is common to find leptospirosis in the water and soil contaminated by rats. ${ }^{\prime}$ (5) More than rat hunting, the Mussahars (even children) are very skilled in squirrel hunting. A study in the USA indicates that squirrel hunting may be associated with leptospirosis. ${ }^{2}$

Apparently all these aspects have not been explored to find out whether any of the members of the community who developed the disease were engaged in any of these activities. The fact that leptospires are quickly killed by salt ${ }^{3}$ (which mus have been used in cooking) and the gastric acidity makes the intestinal mode of transmission a remote possibility.

Paediatric Department,

Joyce Green Hospital,

Dartford,

Kent DAl SPL

1 Ido $\mathrm{Y}$, Hoki $\mathrm{R}$, et al. The rat as a carrier of Spirocheta icterohaemorrhagiae, the causative agent of Weil's disease. I Exp Med 1917;26:341-53.

Diesch SL. Human leptospirosis acquired from squirrels. NEngl f Med 1967;276:838.

3 Duguid JP, Marmion BP, Swain RHA. Mackie and McCartney's medical microbiology. Vol 1. 13th ed. London: Churchill medical microbiology.

4 Kirschner L, Maguire T, Benland WS. British fournal of Experimental Pathology 1951;28:357.

\section{A proposal for doing prevalence studies of AIDS}

SIR,--Our growing knowledge of the consequences of human immunodeficiency virus (HIV) infection gives cause for increasing gloom. That we are facing a major public health disaster is widely acknowledged, and it cannot escape the thoughtful that there could be implications for the economic and political stability of our own and other nations. If the problem is to be contained we urgently require quantitative information about trends in the prevalence of HIV infection and more knowledge about the clinical course of infection. Thus I was saddened to read of the difficulties Sir Richard Doll (24 January, p 244) and his colleagues are encountering with their modest proposal to study the prevalence of HIV.

Admittedly the proposal is crude, but it would considerably improve knowledge about trends in prevalence, and it has the great merit of simplicity. Furthermore, it does not infringe anyone's rights except in a trivial and theoretical way. Indeed, I believe that our plight is. sufficiently serious to justify going further and introducing registries of infected people to enable 'systematic study of the occurrence of morbid events. HIV registers introduce no new ethical principle and would pose no more threat to individual liberty than cancer and mental illness registries. No one has ever been given cause to question the probity of these other kinds of registry.

By coincidence the same issue that contained Sir Richard Doll's letter included a letter from Dr Ian Chalmers (p 247) in which he castigated medical ethicists for their naivety and arrogance. Let us hope that in facing the epidemic of the acquired immune deficiency syndrome we shall not be diverted from necessary action by long discussions with armchair theorists. This national emergency must be faced in a pragmatic manner. Although there should be sensitivity to the rights of the few, it must be acknowledged that the protection of the many may need to take precedence.

A S ST LEGER

Department of Community Medicine,

University of Manchester,

Manchester M13 9PT

SIR,-Sir Richard Doll (24 January, p 244) relates the problems encountered from within the profession of determining the prevalence of infection with human immunodeficiency virus (HIV) in Britain. Anxiety about the possibility of heterosexual spread is now rife, having been fuelled by the government's national publicity campaign. If such spread is to occur it will appear first among patients attending genitourinary medicine clinics in areas inhabited by high risk groups.

In collaboration with the Virus Reference Laboratory at Colindale, selected women attending such a clinic at West London Hospital since December 1984 have been screened for HIV antibody. Patients with five or more sexual partners during the preceding 12 months were selected. The two patients who attended immediately before and after each test patient and who reported fewer recent partners were used as controls. During this period the seroprevalence among homosexual men attending the clinic has remained in the region of $30 \%$

To date 213 serum samples from women have been tested, of which $78(37 \%)$ were from the test group. None of the samples has contained HIV antibody. The results of this small sample are encouraging, but without further studies of this kind the actual risk to sexually active women will remain unknown. If substantial heterosexual spread of HIV were to occur it would have to reach dangerous proportions before overt disease led to its detection. Such a delay would be unacceptable.

B A Evans

Department of Genitourinary Medicine,

West London Hospital,

London W6 7DQ

SIR,- The signatories of this letter, who are all consultant microbiologists in the Northern region, are concerned at the lack of information available on the prevalence of infection with the acquired immune deficiency syndrome (AIDS) in the general population other than blood donors. We consider that it is fundamental to the study and control of any infectious disease that an estimate of the pool of infection should be made and to that end consider that some degree of screening should be introduced.

Although we are sensitive to the objections made to screening without prior consent or any form of counselling, we feel that there is ample precedence for this in the way we screen antenatal patients for syphilis and other groups of patients for hepatitis. As we are already aware of the presence of individuals positive for human immunodeficiency virus (HIV) in certain high risk groups 